\title{
A Review of Soil Erosion Estimation Methods
}

\author{
Amílcar Mateus de Oliveira Salumbo \\ Faculdade de Ciências Agrárias, Huambo, Angola \\ Email: asalumbo@hotmail.com
}

How to cite this paper: Salumbo, A.M. de O. (2020) A Review of Soil Erosion Estimation Methods. Agricultural Sciences, 11, 667-691.

https://doi.org/10.4236/as.2020.118043

Received: July 1, 2020

Accepted: August 2, 2020

Published: August 5, 2020

Copyright (c) 2020 by author(s) and Scientific Research Publishing Inc. This work is licensed under the Creative Commons Attribution International License (CC BY 4.0).

http://creativecommons.org/licenses/by/4.0/

\begin{abstract}
Soil erosion has been seen as a major contributor to the loss of soil fertility and land degradation in many parts of the world. It is a very sensitive process for agriculture, since it is linked to the decrease of crops productivity along the time. Although it occurs in almost all latitudes on the planet, its effect is particularly severe in tropical climates, mainly due to frequently high rainfall intensities in those areas. The measurement of soil loss on experimental plots has provided valuable information for soil conservation plans, and data collected have contributed to deriving methods and equations that can estimate the extent of soil water erosion occurring under certain conditions. However, these methods are data hungry, and a solid research framework is needed to provide the required information to validate and use different models and equations generated elsewhere, to calculate the rate of erosion in a given place. Because estimating erosion rates is critical for conservation planning, the best fit models need to be well chosen and applied according to the local conditions. This article provides a review of some of the most used models for soil erosion estimation, with the purpose to provide some guidance to those involved in these studies.
\end{abstract}

\section{Keywords}

Soil Erosion, Land Degradation, Estimation, Soil Conservation, Models

\section{Introduction}

The estimation of the amount of soil that is lost due to water erosion for land use planning and to adopt soil conservation measures, has been done through different methodologies, of greater or lesser complexity, since the factors that determine erosion to be considered depending on the available data. In a generic way, one can identify 1) methods of prospecting erosion, which use observation of visible signs of erosion, 2) methods which use the mapping of factors that determine the risks of erosion, 3) and methods using soil loss models. This is not a 
strict division since the boundaries between these methods are not well defined; there is generally overlap and complementarity between them.

Of the prospecting methods, the use of aerial photography and the mapping of signs of soil loss are highlighted. Visible signs of soil degradation were mapped [1], such as the distribution of laminar and furrow erosion, as well as the factors considered as determining the potential risks of erosion, namely the topography of the terrain, the soil erodibility, the amount of precipitation and predominant land use. In England and Wales aerial photographs and field surveys were used to locate erosion by measuring, where possible, the quantities of soil lost, and details of land use and cultivation systems were also obtained to identify factors affecting erosion [2]. Aerial photography was also used in the lowlands of England [3] to list erosion fields, having located 477 fields with this problem.

In order to identify and classify sites according to the nature and importance of erosion risks in river basins located north of Paris, without permanent channels, where the valley floor is used as agricultural land, an erosion risk assessment was carried out based on the classification of each erosive form, and a multi-criteria hierarchy for each basin according to the importance of the erosion forms observed [4]. In Denmark, an erosion risk chart was prepared using a soil database and morphological maps based on the USLE LS factor (point 2.1) [5], and in the United States [6] prospected for laminar and furrow erosion in cultivated land, pastures, forests, abandoned and urbanized land in Maryland, using USLE. To the northeast of Alberta, Canada, [7] mapped the risks of potential water erosion on small plots of land using USLE and aerial photographs, maps and soil data, having defined six risk classes, from negligible $\left(<6 \mathrm{t} \cdot \mathrm{ha}^{-1} \cdot \mathrm{year}^{-1}\right)$ to extreme $\left(>55 \mathrm{t} \cdot \mathrm{ha}^{-1} \cdot \mathrm{year}^{-1}\right)$. The use of photogrammetry, to evaluate the movement of the soil by the concentrated flow in hydrographic basins mined in a conventional and conservative way, is also mentioned [8].

In some studies, erosion factors (point 2.1) were used to characterize the risks of soil loss occurrence. Soil erodibility, vegetation cover and land use were mapped [9] from a survey using aerial photography, in Mérida, Spain, having classified as part of the "erosion susceptibility" the part of the risk of erosion caused by factors relatively such as climate, terrain and soil, the remainder of the risk being determined by the effect of vegetation cover and land management in a specific situation.

Slope angle and slope length were used to characterize the risk of erosion in Hungary [10], while for some European countries, such as Belgium, Holland, Germany, France and the United Kingdom, different indices were used, such as the EI30 (4.1.2) and Fournier F (4.1.2) to map the risk of erosion [11]. Correlations between annual average precipitation values and the EI30 index were made [12], and between this and the modified Fournier index, in three locations in southern Portugal, which allowed obtaining an isoline chart of the latter index. Based on the transformation of the Fournier index into the EI30 index, a preliminary isoerodent chart was prepared, with the aim of serving as a valuable 
tool for planning soil conservation in that region.

In order to test the validity of USLE for African conditions [13] compared the values obtained with its application in West Africa with experimental data obtained by the French Overseas Research Office (ORSTOM) and the French Research Institute Applied (GERDAT), having concluded that the equation seemed to adapt well to most soils cultivated in the region and moderate slopes, particularly in tropical ferralitic and ferruginous soils. A factorial classification method for erosion mapping was developed in Zimbabwe [14], in which the factors of erosion-precipitation erosivity, soil erodibility, slope, cover and human influences-were individually classified and their sum resulted in an erosion risk category. The Soil Loss Estimator Model for Southern Africa (SLEMSA) (point 2.3), to assess soil losses by laminar erosion and furrows in arable land, resulted from the classification technique factorial [15] based on the physical systems climate, soil, topography and culture, and the influences of natural properties and human intervention were considered within the appropriate system.

A modified SLEMSA methodology that was used to develop a regional erosion risk chart for southern Africa was presented, in which the erosion risks were presented as Erosion Hazard Units (EHU) (Erosion Hazard Units) and not in estimating the amount of soil lost, in tons per hectare per year [16].

The modeling of erosion processes with physical basis, has been the trend of evolution of studies on the evaluation of soil losses, for conservation planning purposes. According to [17] erosion modeling consists of mathematically describing the removal of soil particles, transport, and deposition on the land surface. Examples of this new approach are several works that are being carried out with increasing emphasis. [18] worked on modeling the erosion caused by the impact of rain on the soil, studying the relationship between the thickness of the water film on it and the size of the water droplets, and [19] tested a model to predict events of runoff and soil loss to allow the determination of the risk of erosion, according to the plant's growth phase and other factors related to time.

Other works of the kind are mentioned by [20], on erosion modeling in watersheds, [21], modeling rill erosion and [22], who investigated the applicability of various sediment transport equations under various hydraulic conditions, including laminar flow. [23] carried out a mathematical design study to calculate changes in soil erodibility over time, and [24] developed an erosion model for Kentucky (USA), called KYERMO (Kentucky Erosion Model), with the aim of serving as a research tool to isolate the important aspects of the erosion process linked to the precipitation/runoff relationship.

The CREAMS model (Chemicals Runoff Erosion in Agricultural Management Systems) is referred to by [25] as basically containing components to simulate the physical processes that control hydrology, erosion/sediment production and the movement of chemicals in an agricultural plot. They emphasize that this model incorporates a large number of variables that are necessary to describe and estimate soil losses in plots with or without drainage channels. In turn, [26] 
present a runoff model based on the runoff equation modified by the US Soil Conservation Services (SCS) and a soil moisture assessment process to simulate the daily, monthly and annual runoff of a small hydrographic basin ( $<50 \mathrm{ha})$.

[27] present the WEPP model designed to simulate the transport of sediments and to estimate the processes of laminar and furrow erosion, with erosion represented as a function of the intensity of precipitation, cover by waste, cover by canopy and soil erodibility. Later, an evaluation of the response of this model to the change of input parameters was made, and it was concluded that the big difference between the WEPP (Water Erosion Prediction Project) and the RUSLE (Revised Universal Soil Loss Equation) is that the first estimates the deposition [28] while the second estimates sediment production.

Based on the argument that models such as USLE (Universal Soil Loss Equation) or CREAMS cannot be transported to Europe without calibration, [29] present the European erosion model (EUROSEM) (European Soil Erosion Model) to support the development of strategies for soil protection. The model calculates soil losses by comparing the flow carrying capacity with the amount of sediment available for transportation through the removal process, and erosion can be limited both by the amount of sediment removed and the flow carrying capacity. It is designed to operate for successive periods of time within a rain, usually from one to five minutes, and simulates changes in the soil surface during the rainy event in terms of microtopographic roughness, water storage on the soil surface and cohesion of the soil surface material.

Although the physically based models are presented as an alternative to the empirical ones for estimating soil losses, they are not perfect in describing the erosive phenomenon. To confirm this, having carried out an investigation work with the aim of studying the problems of identifying the parameters for the physically based models of simulation of erosion, [30] concluded that the mathematical models that describe the laminar and rill flow, the removal of sediments and their transport and deposition are based on simplified assumptions, which are always an abstraction from reality. Even so, more and more attention has been placed on improving this type of erosion assessment models. According to [31] physically based models have the advantage of incorporating the laws of conservation of mass and energy, as most of them use a particular differential equation known as the continuity equation which is a statement of the conservation of matter as it moves through space and time. There is an input of material to the segment as a result of detachment of soil particles on the segment itself and an influx of sediment from the slope above. If the material removed can be transported by the flow there is soil loss, and there is deposition when the transport capacity of the flow is less than detachment.

\section{Erosion Prediction Models in Agricultural Soils}

The estimation of soil loss that occurs in some areas, under specific conditions of action of erosion factors and agricultural land use, can be done using empirical 
models that are described in a summarized way in this text. Among the various existing methodologies for quantitatively assessing soil erosion, those that best fit the availability of data in the study areas can be chosen given their adaptability to regions with conditions close to those in these study areas. Despite this, the available data may be insufficient to apply these models according to standardized methods, which can motivate the need to make some adjustments and adaptations in the process of determining erosion factors.

\subsection{Universal Soil Loss Equation (USLE)}

USLE is the most widely used method of estimating soil loss by conservationists in the United States of America, having been adapted for the same purpose in other countries [32]. According to [33] the USLE is an empirical erosion model designed to estimate long-term mean soil losses from runoff in field areas, crops and specific cultivation methods, and which can still be useful for construction areas and other non-agricultural conditions, but which does not estimate deposition nor calculate sediment production by erosion in ravines, banks and riverbeds.

The general equation is of the form:

$$
A=R K L S C P
$$

where, when in metric units:

$$
\begin{aligned}
& A=\text { loss of soil (t/ha.year), } \\
& R=\text { rain erosivity factor (MJ.mm/ha.h), } \\
& K=\text { factor of soil erodibility (t.h/MJ.mm), } \\
& L=\text { slope length factor (dimensionless), } \\
& S=\text { slope factor (dimensionless), } \\
& C=\text { land cover factor and cultural operations (dimensionless), } \\
& P=\text { factor of conservative practices (dimensionless). }
\end{aligned}
$$

In order to obtain the final result of the estimate of soil losses, each erosion factor is determined according to a specific procedure.

\subsubsection{Rainfall Erosivity}

The $R$ factor quantifies the capacity of rainfall to cause the detachment and transport of soil particles by the action of the impact of water droplets and by runoff [34], being defined using the product of two characteristics of the rain, namely kinetic energy $(E)$ and maximum intensity in 30 minutes (I30). Originally the unit kinetic energy of precipitation is determined by the following equations [35]:

$$
\begin{gathered}
E=0.119+0.0873 \log _{10} I \quad \text { if } I \leq 76 \mathrm{~mm} / \mathrm{h} \\
E=0.283 \text { if } I \geq 76 \mathrm{~mm} / \mathrm{h}
\end{gathered}
$$

[32] justifies the differentiation of these two situations by the fact that some studies have shown that the average diameter of raindrops does not continue to increase with intensities above $76.2 \mathrm{~mm} / \mathrm{h}$. The total energy of each rainy event can be obtained by accumulating the kinetic energy of each portion of intensity 
of the event. Knowing the value of 130 from the analysis of the graphical record of each event, the respective EI30 value can be found and its sum for a period of one year, corresponds to the erosion index of the USLE. For it to be representative, it must correspond to the average of a sufficiently long period, at least not less than 20 years, according to [36].

There are references to several other expressions that make it possible to determine the kinetic energy of precipitation, of which [37] derivative in Africa stands out, based on the argument that erosion has little significance at low rainfall intensities, thus deriving the KE index $>25$ which is defined as the total energy of rain that falls at intensities greater than $25 \mathrm{~mm} / \mathrm{h}$. The expression that allows calculating this index has the form:

$$
\mathrm{KE}=29.8-\frac{127.5}{I}
$$

where $\mathrm{KE}$ is the kinetic energy of rainfall with an intensity greater than 25 $\mathrm{mm} / \mathrm{h}$, in $\mathrm{J} \cdot \mathrm{m}^{-2} \cdot \mathrm{mm}^{-1}$, and $I$ is its intensity $(\mathrm{mm} / \mathrm{h})$. [38] refers to a study, carried out in northern Nigeria, of correlation between the kinetic energy of KE rainfall, in ergs. $\mathrm{cm}^{-1}$, and the height of rain $\left(R_{a}\right)$ in $\mathrm{mm}$, which resulted in the expression:

$$
\mathrm{KE}=41.4\left(R_{a}-120.0\right) \times 10^{3}
$$

A modified version of USLE, called MUSLE, was used by [39] to assess erosion and runoff in Hawaii. In this version, the rainfall energy factor, $R$, is replaced by a flow factor taking the equation as follows:

$$
Y=11.8\left(Q \times q_{p}\right)^{0.56} K C P L S
$$

being:

$Y=$ sediments collected in each individual rain,

$Q=$ flow volume,

$q_{p}=$ peak flow rate of the flow.

The other factors are the same as those at USLE.

There are several other relationships that are also used to estimate the rainfall erosivity.

\subsubsection{Soil Erodibility}

The soil erodibility factor is defined by [33] as the rate of soil loss per unit of erosion index, measured in a standard plot arbitrarily defined as having a length of $72.6 \mathrm{ft}(22.1 \mathrm{~m})$ in which the slope is uniform and $9 \%$, on continuously bare soil and plowed in the direction of the largest slope. This is a quantitative value that is determined experimentally [34], and can be estimated according to the physical, chemical and mineralogical properties of the soil using the soil erodibility nomogram that relates it to five soil parameters: percentage silt and very fine sand $(0.002-0.1 \mathrm{~mm})$; percentage of sand $(0.1-2 \mathrm{~mm})$; percentage of organic matter; soil structure (classified in 4 classes) and soil permeability (classified in 6 classes, adopting the lowest value among the profile horizons). This in- 
dex can also be calculated, for soils containing less than $70 \%$ of silt and very fine sand, by the following algebraic expression [33]:

$$
K=2.1 M^{1.14}\left(10^{-4}\right)(12-a)+3.25(b-2)+2.5(c-3) / 100
$$

on what:

$K$ is the erodibility index (t.h/MJ.mm),

$M$ the particle size parameter equivalent to the product of (\% slime $+\%$ very fine sand) per (100 - $\%$ clay),

$a$ the percentage of organic matter,

$b$ the soil structure class,

$c$ the permeability class of the soil profile.

These alternatives are of great use when it is intended to estimate the erodibility of a soil for which this value has not been obtained in erosion plots. As [36] refer, direct measurements of the $K$ factor require considerable time and equipment and are costly to perform.

\subsubsection{Topographic Factor}

The LS factor is defined by [33] as the expected rate of soil loss per unit area of a hillside in a field, in relation to what happens in a standard plot with $22.1 \mathrm{~m}$ in length and 9\% slope. It includes the combined effect of the slope length and the grade of the slope, although these can be assessed individually. [36] define the slope length as the distance from the point of origin of the runoff to the point where the slope decreases sufficiently for deposition to occur, or the point at which the runoff enters a defined channel.

These parameters can be determined by expressions that relate them. [38] present the following expressions for their estimate:

$$
L=\left(\frac{\lambda}{22}\right)^{m}
$$

being $\lambda$ the length of the slope in meters, $m$ equal to 0.2 if the slope $(s)$ is $<1 \%$,

$$
\begin{gathered}
0.3 \text { if } 1 \%<s<3 \%, \\
0.4 \text { if } 3.5 \%<s<4.5 \%, \\
0.5 \text { if } s>5 \% .
\end{gathered}
$$

To determine the value of $S$ :

$$
\begin{gathered}
S=3.0(\operatorname{sen}(\theta))^{0.8}+0.56 \text { if } L<4 \mathrm{~m}, \\
S=10.8 \operatorname{sen}(\theta)+0.03 \text { if } L>4 \mathrm{~m} \text { and } S<9 \%, \\
S=16.8 \operatorname{sen}(\theta)-0.50 \text { if } L>4 \mathrm{~m} \text { and } S \geq 9 \% .
\end{gathered}
$$

$\theta$ is the angle of inclination of the field or plot (degrees). The LS index can be calculated by the expression [36]:

$$
\mathrm{LS}=\left(\frac{\lambda}{22.13}\right)^{m}\left(0.065+0.045 s+0.0065 s^{2}\right)
$$


being $\lambda$ the length of the slope in meters and having $s$ and $\mathrm{m}$ the same meaning mentioned above. To determine this index [13] presents another expression with a similar format:

$$
\mathrm{LS}=\frac{\sqrt{\lambda}}{100}\left(0.76+0.53 s+0.076 s^{2}\right)
$$

where $\lambda$ is the length of the slope in feet. With slopes lower than $1 \%$, results are significantly different for LS using the two expressions, which does not happen with $s$ values above $5 \%$.

\subsubsection{Land Cover and Cultural Operations Factor (C)}

It corresponds to the ratio between the loss of soil that occurs in plowed land under certain conditions, and that occurring in continuously plowed and bare ground [33]. According to [36], this factor integrates the interrelated effects of soil cover, the sequence of crops, the level of productivity, the length of the plant growth period, cultural practices, crop residue management, and the precipitation distribution. Its assessment is difficult given the existence of many cultivation and crop management systems.

The determination of factor $C$ for a location depends on how the erosive precipitation is distributed throughout the year and on the protection that plants, their residues and cultural practices provide to the soil, mainly during the periods when the rains are most erosive. [34] refer that $C$ is determined by several interactive variables, namely the culture, the residues placed on the surface or mulch, the residues incorporated in the soil, the mobilizations and the previous use of the soil.

The methodology for calculating the $C$ value is detailed by [33]), essentially consisting of the definition of plant growth stages, ranging from soil preparation, through sowing to harvesting and treatment of crop residues, and knowledge of the erosivity distribution over this period. They provide tables and examples for determining this factor using data from the United States with individual cultures and crop rotations, and local data can be used to estimate this factor according to this procedure.

\subsubsection{Factor in Erosion Control Practices $(P)$}

It is defined as the ratio between the erosion that occurs under the use of specific soil conservation practices and that which occurs under cultivation in the sense of the greatest [36]. These conservative practices are usually tillage according to contour lines, cropping in contour lines and terracing, while practices such as conservative tillage, crop rotations, fertilization, and waste use are important conservation practices that are included in the crop management factor $C$.

This factor is normally used as an element to correct erosion that occurs under certain conditions of land use, allowing the selection of the most appropriate conservation measure to lower soil losses to a level that does not reduce the productive capacity of the land, being therefore an element applied essentially to 
the planning of agricultural conservation use of the soil. [33] present tables of $P$ values for different conservative practices, such as crops on contour lines, contour lines and terraces, according to the characteristics of the terrain. A conservationist can select among these conservation practices which ones are most suitable to apply to a certain field condition in order to bring erosion to a minimum allowable value, considering the crop being grown, the soil and climate in the location.

\subsection{Revised Universal Soil Loss Equation (RUSLE)}

The RUSLE is an empirical model that conserves the basic structure of the USLE, with regard to the main equation, the same being the factors that determine soil losses through erosion, with the difference that these are calculated according to different procedures, involving treatment per computer. According to [40], RUSLE is a powerful tool for planning and conservation, for inventorying erosion rates in vast areas, and for estimating sediment production, which can become a sediment harvest in watersheds, and can be used on farmland, pastures, disturbed forests, construction sites, and other areas where runoff occurs as a result of greater rainfall than infiltration.

Regarding the erosivity of precipitation, [41] highlight the main differences of this model in relation to the USLE, being these: the new trend of the $R$ factor to reduce its values in flat places of regions with intense rains, since the water retention at the surface when runoff occurs reduces rainfall erosivity; the fact that part of the calculation of the factor $R$ involves a seasonal distribution to allow the weighting of the value of the soil erodibility, $K$, and the coverage factor and cultural practices to be weighted. For this purpose, files with climate data were developed for climatically homogeneous areas, called city codes, which integrate information on the number of days without soil ice formation, monthly precipitation and temperature, and the distribution of rainfall over periods of 15 days. It should be noted that the program provides space to add data sets provided by the user, which should allow its easy use in other regions of the world.

To calculate the unit energy of the rain, a new equation is presented [42] of the form:

$$
e_{m}=0.29\left[1-0.72 \exp \left(-0.05 I_{m}\right)\right]
$$

in which:

$e_{m}$ is the maximum unit energy when the intensity tends to infinity, in $\mathrm{MJ} \cdot \mathrm{ha}^{-1}$,

$I_{m}$ the maximum rainfall intensity in $\mathrm{mm} \cdot \mathrm{h}^{-1}$.

The soil erodibility factor, $K$, has been updated by integrating equations to calculate its value for soils with little data, such as lack of information on the fraction of sand or organic matter, and with a textural composition given by a classification system different from that used in the USA [34]. It also includes equations to estimate the $K$ value in conditions not covered by the nomogram, such as volcanic soils and with a high content of organic matter (Renard et al. 
1995).

According to [41], erodibility data from several locations in the world were reviewed, which allowed the development of an equation that gives an estimate of the $K$ value as a function of the average diameter of the soil particles. The authors also refer to the consideration of the seasonal variability of erodibility in RUSLE, by weighting the estimated value of $K$ in proportion to the annual percentage of EI in 15-day intervals, with instantaneous estimates of $K$ being made by equations that relate it to the period without occurrence of ice in the soil and with the annual value of erosivity. They also note the consideration of the effects due to stone fragments on and in the soil. Those on the surface are taken as a mulch in factor $C$, while the fragments incorporated in the soil profile are considered to adjust the erodibility value, to take into account the effects on runoff.

RUSLE uses three slope length ratios, which are functions of soil susceptibility to rill erosion in relation to interrill erosion, and a fourth ratio that is specific to the Northwest Pacific cereal production areas in the USA, and it has a closer relationship to the linear with the degree of the slope than the USLE [43]. Also mentioned is the ease with which the model can represent the real topography of a slope segment, which was considered to be uniform, which led to gross errors in the estimation of the LS factor. In this model, and in your computer program, complex slopes can be easily represented to give a better approximation to the topographic effect [41].

To determine the factor of soil cover and cultural operations, $C$, RUSLE uses a subfactorial method to calculate soil loss rates (SLRs) as a function of four subfactors, according to the formula [41]:

$$
C=\mathrm{PLU} \cdot \mathrm{CC} \cdot \mathrm{SC} \cdot \mathrm{SR}
$$

being:

PLU the previous land use,

$\mathrm{CC}$ the coverage by the culture crown,

SC the degree of coverage of the soil surface,

SR the roughness of the soil surface.

In areas where vegetation reaches a certain balance, such as in natural pastures and scrub, these parameters are barely changeable over time, resulting in a small variation in the calculated rate of soil loss, which leads to the option of calculating a value single SLR for the whole year, while on cultivated land, or on pastures where the soil is mobilized, these parameters vary throughout the year, so the SLR values must be calculated in order to take into account the variations over the year. year or rotation [34]. It is also considered that these factors remain constant for a period of 15 days, for which it is proposed to calculate the SLR for RUSLE.

A fifth factor for determining SLR, namely the soil moisture subfactor used in the US Pacific Northwest cereal production areas, (SM), is introduced in the expression (2.15) [34] [43]. According to [41] the factor of the degree of coverage 
of the soil surface has the greatest effect on erosion, with RUSLE having a value of 1.0 minus the percentage of bare soil, which reflects the addition of dead matter in the form of rock and stone to conventional dead plant matter. [43] state that one of the reasons for RUSLE's subfactorial approach is to accommodate applications in which SLR values are not available, such as cultures that are not represented in the computer program.

As at USLE, at RUSLE the values of factor $P$ are the least accurate and generally represent the general effects of conservation practices. According to [41] extensive data, both in the field and in the model, were analyzed to reevaluate the effect of the crop according to the level curves, and the results were interpreted to provide factor values for this practice as a function of the ridge height, level furrows, and climate erosivity. The new values for the factor $P$ due to the terracing take into account the slope along the terrace, while considering a wider range of culture conditions in bands than that considered in the USLE. It should be added that in RULSE values of factor $P$ were also developed, which reflect conservation practices in pastures.

\subsection{Soil Loss Estimation Model for Southern Africa (SLEMSA)}

This methodology is considered to be particularly appropriate for countries that, although urgently in need of measures to combat erosion, have resource limitations to support the expenditure of research programs, and was designed to estimate the average annual soil loss due to sheet erosion that occurs on arable land between two adjacent ridges [44]. It results from research studies carried out in southern African countries, mainly Zimbabwe, and South Africa, and was initially developed for the first country.

The structure of the model is represented in Figure 1, which shows that it is basically composed of four components, namely the physical systems, the control

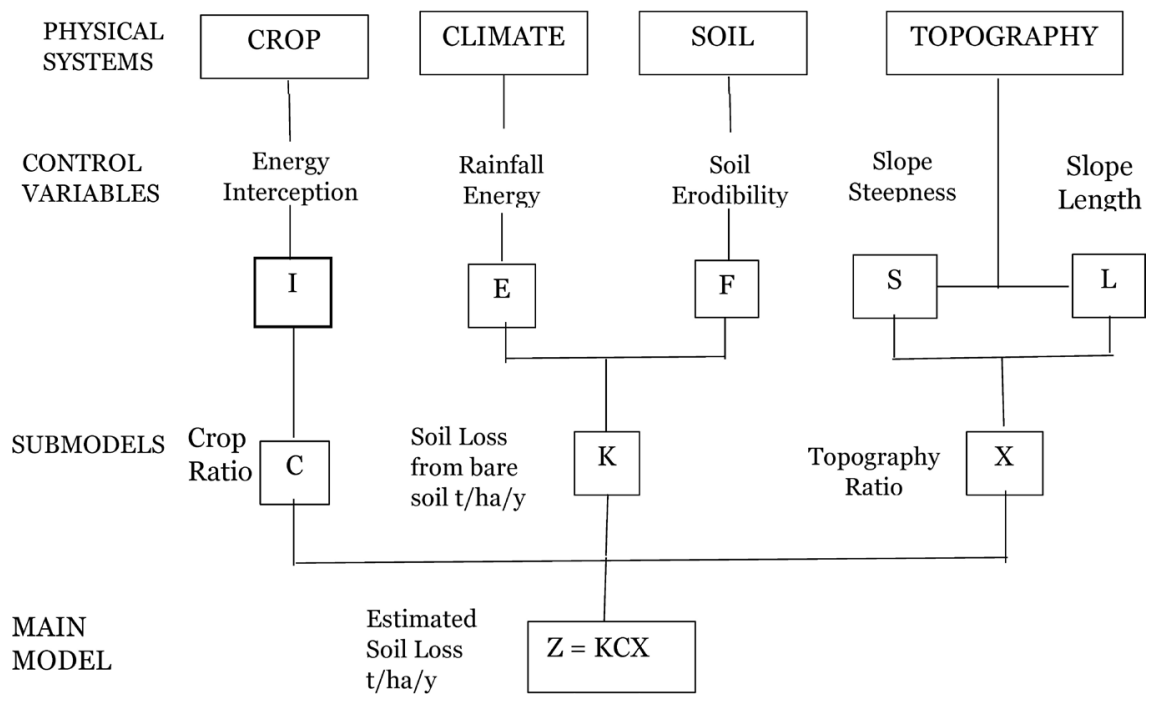

Figure 1. Diagram of the structure of the model for estimating soil loss for Southern Africa (SLEMSA) [44]. 
variables, the sub-models and the main model, each of them treated separately. The model considers that erosion depends on four physical systems that are culture, climate, soil and topography, each of which is defined by a control variable. The variable that defines the crop influence on erosion is the percentage of rain energy intercepted, the climate is defined by the energy of precipitation, the soil by its erodibility index and the topography by the degree of slope or inclination of the land and the length of the land hillside.

[44] considers that for this model any practice that has an influence on soil properties, such as tillage or other treatment, is taken into account in the soil system and any other factor related to culture is integrated into the culture system, arguing that this approach differs in concept from USLE in that tillage and cultivation are both part of the factor of cultures and cultural practices, $C$. This differentiation is discussed by [45] for whom the basic approach of the SLEMSA model is very similar in concept to USLE.

Each of the referred parameters can be determined using expressions that relate them to their control variables. The final result is the main parameter $Z$, which represents the loss of arable soil and results from the product between submodels $\mathrm{Cb}, K$ and $X$. Figure 2 shows how the model relates the variable soil loss in an uncovered surface and in fallow, $K$, with precipitation energy, $E_{p}$, and soil erodibility, $F$.

The expression that translates the relationship between these factors takes the form:

$$
K=\exp \left((0.4681+0.7663 F) \ln E_{p}+2.884-8.1209 F\right)
$$

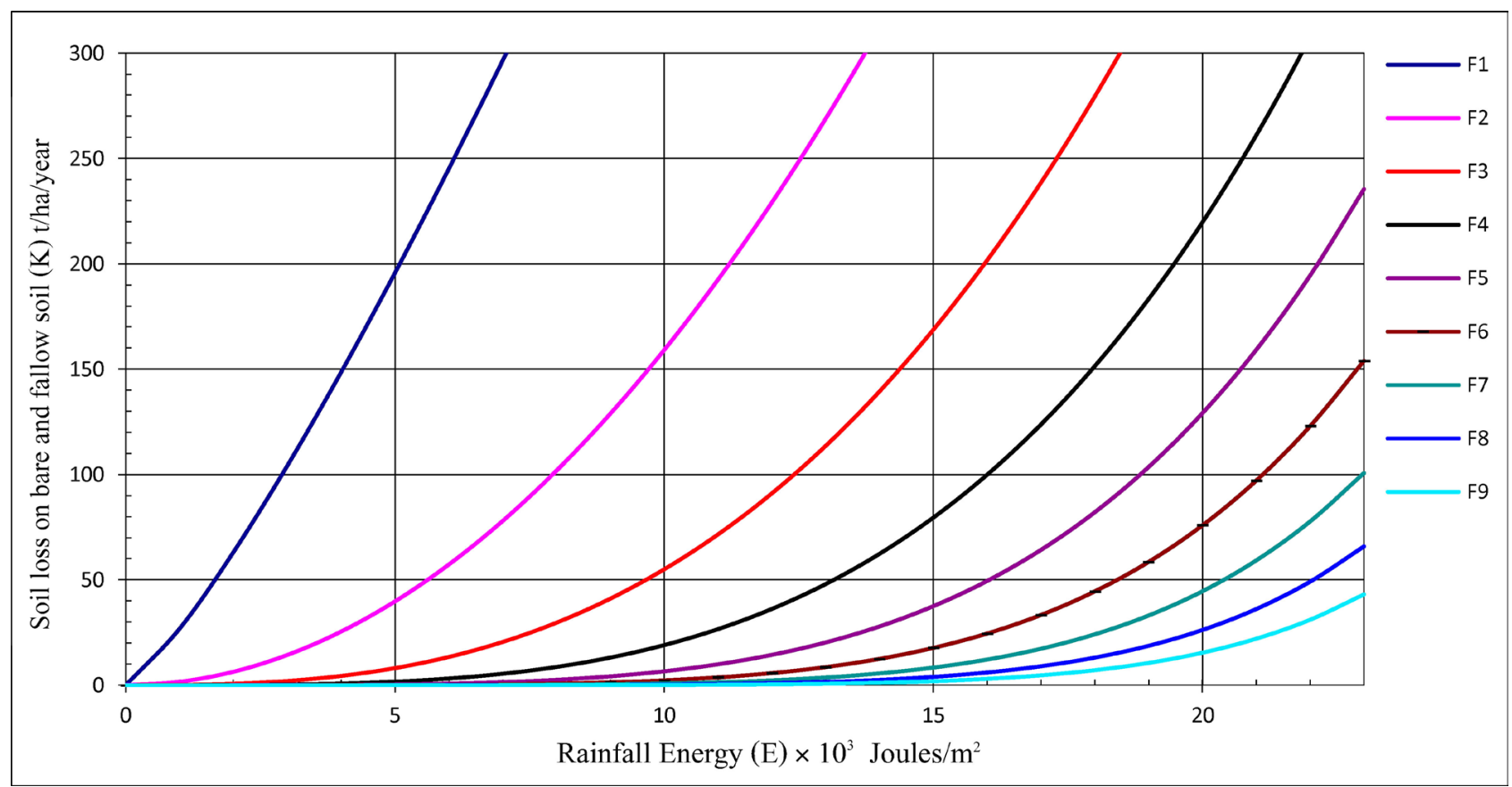

Figure 2. Relationship between erosion in bare and fallow soil $(K)$ with the energy of rainfall $\left(E_{p}\right)$ and soil erodibility $(F)$. From [44]. 
The energy intercepted by the vegetation cover (in\%) is related to the dimensionless variable crop ratio $\left(C_{b}\right)$ by the shape that is represented in Figure 3. $C_{b 1}$ represents the vegetation cover condition of natural crops and pastures and $C_{b 2}$ applies to dense and mulch pastures. The expressions corresponding to each of these parameters are as follows:

$$
\begin{gathered}
C_{b 1}=\mathrm{e}^{(-0.06 i)} \quad \text { when } i<50 \% \\
C_{b 1}=(2.3-0.01 i) / 30 \text { when } i \geq 50 \% \\
C_{b 2}=\mathrm{e}^{(-0.06 i)} \text { when } i \geq 50 \%
\end{gathered}
$$

The way in which the rate of soil loss $(X)$ varies according to the degree of the slope and the length of the slope is shown in Figure 4. The expression that lists these parameters is as follows:

$$
X=\sqrt{\lambda}\left(0.76+0.53 S+0.076 S^{2}\right) / 25.65
$$

where $\lambda$ is the length of the slope in meters and $S$ the degree of the slope in (\%). The figure refers to slopes greater than $4 \%$. For values below this, the relation shown in Figure 5 applies, in which Equation (2.19) is equally valid.

[16] presents two regression equations that relate the seasonal average energy of precipitation with its annual average, according to the type of rain dominant

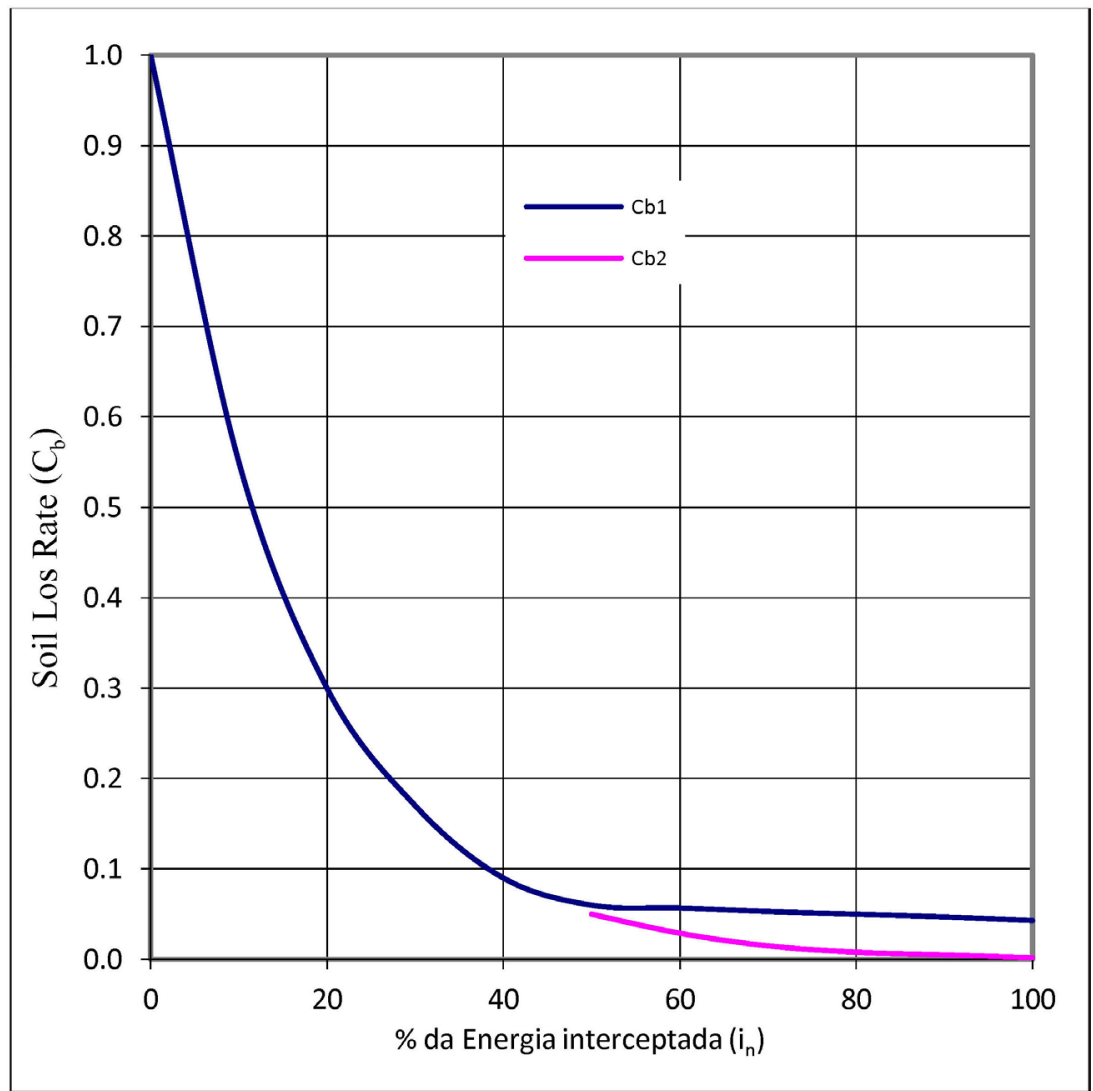

Figure 3. Relationship between the energy intercepted by the vegetation cover and the sub-model of the soil loss rate $\left(C_{b}\right)$. From [44]. 


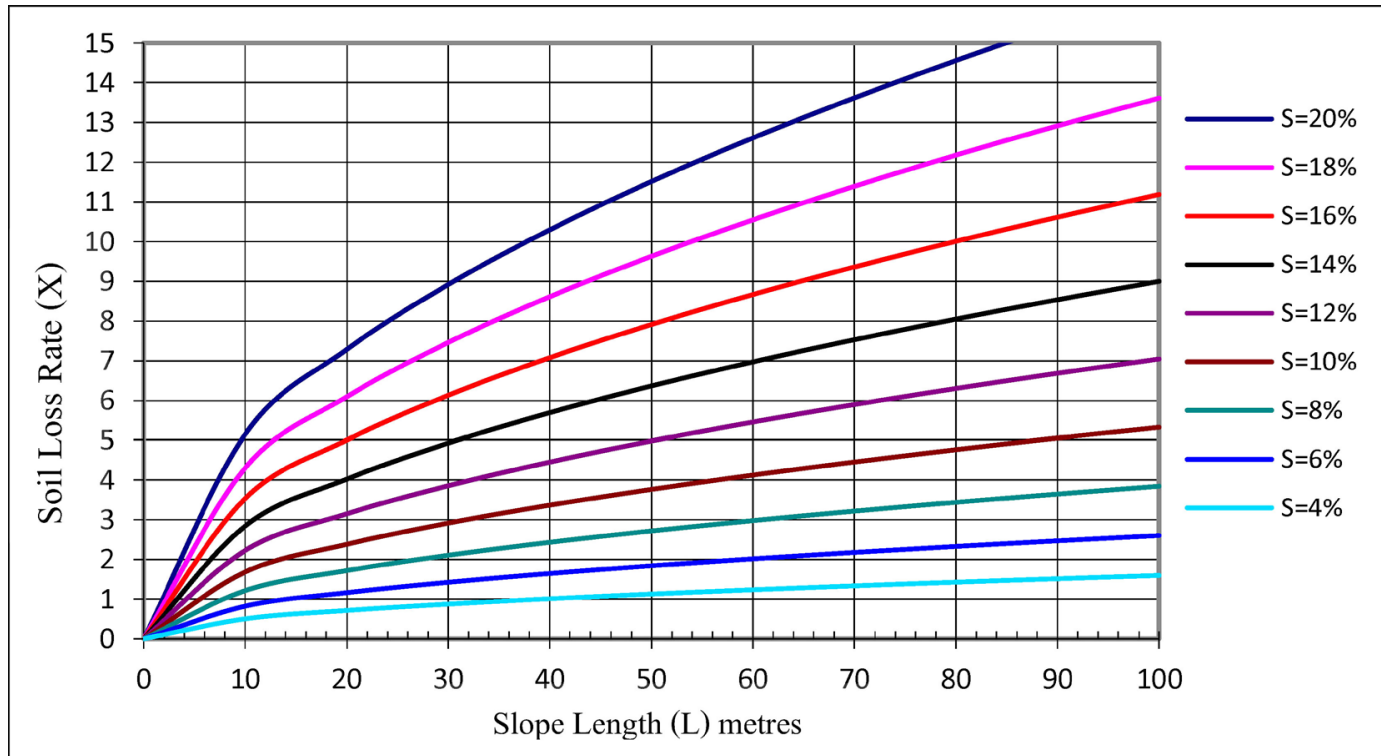

Figure 4. Relationship between the length of the slope and the rate of soil loss $(X)$. Topographic model for $S>4 \%$. From [44].

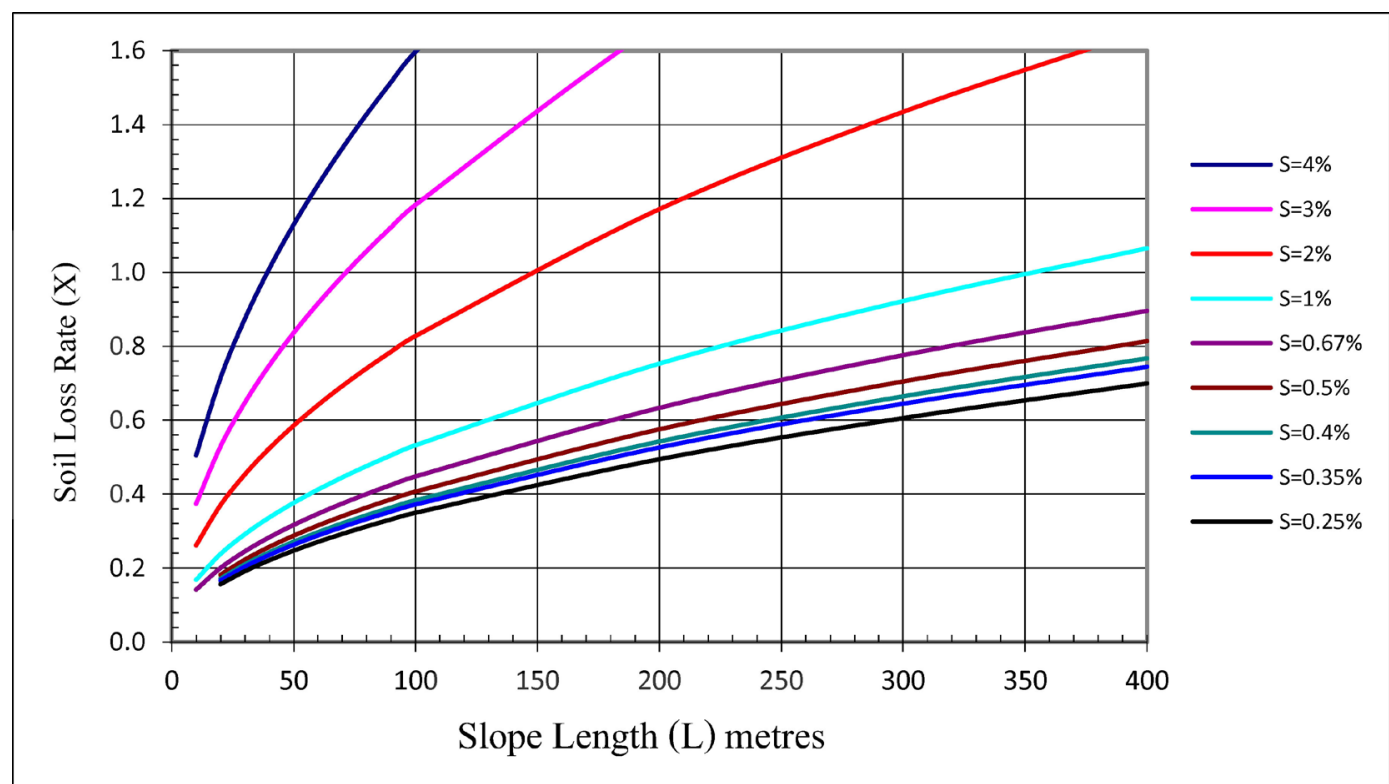

Figure 5. Relationship between the sub-model of the soil loss rate $(K)$, the length and degree of the terrain slope, for slopes less than $4 \%$. From [44].

in a given location. Figure 6 represents this relationship that the model integrates as an alternative to determine the control variable seasonal average energy of precipitation $\left(E_{p}\right)$, whose equations are as follows:

$$
\begin{aligned}
& E_{p 1}=18.846 \times P_{a} \\
& E_{p 2}=17.368 \times P_{a}
\end{aligned}
$$

where $P_{a}$ represents the average annual rainfall in $\mathrm{mm}$. The first expression applies to conditions of occurrence of torrential rains, the second most appropriate 


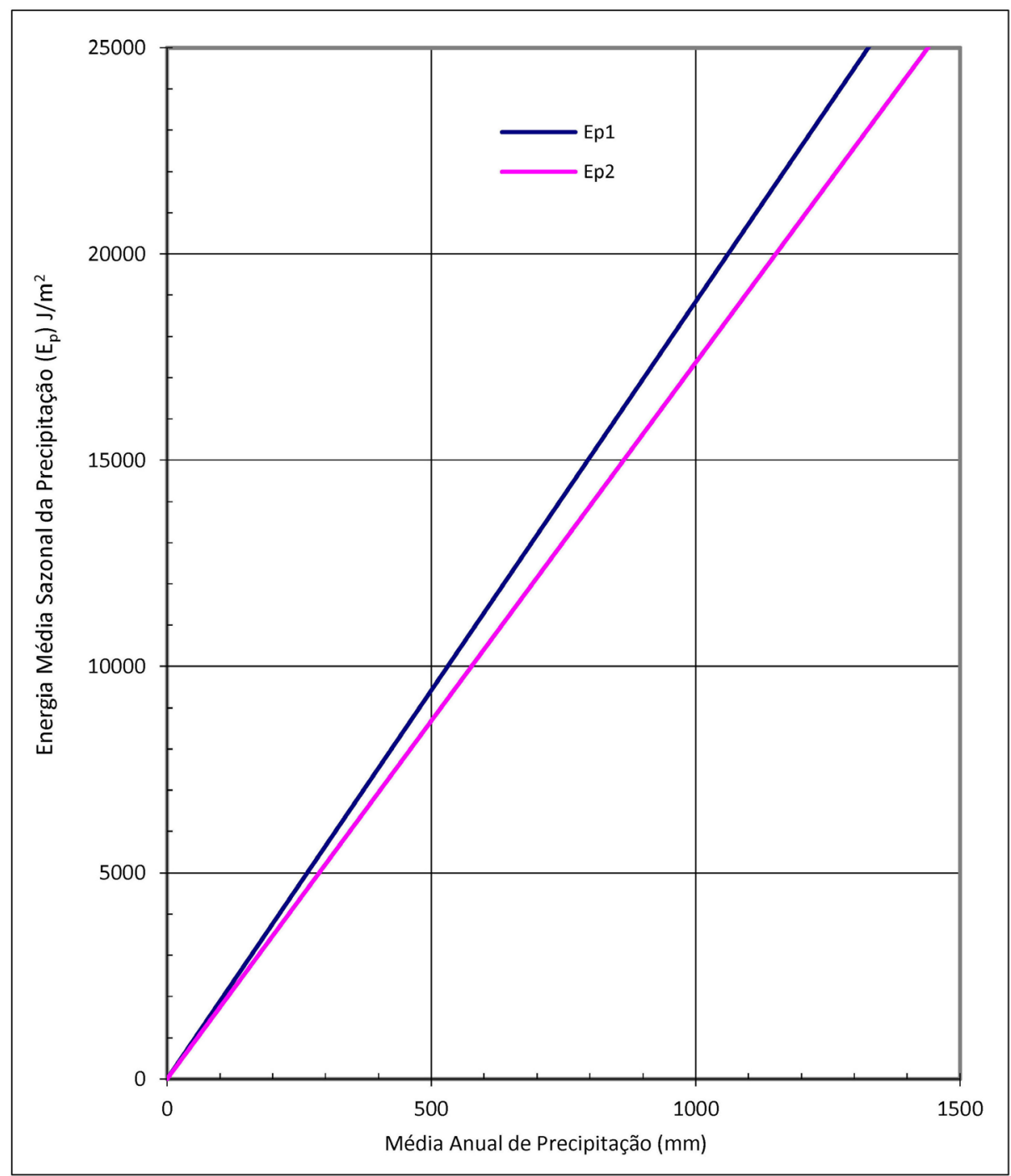

Figure 6. Relationship between the annual average rainfall and the seasonal average of energy of rainfall for two types of rain. From [16].

for conditions of areas with drizzle and light rain. Both expressions were obtained for conditions in Zimbabwe. According to [44], this model offers a means to make decisions based on limited resources and was designed to protect arable land from the effect of erosion.

\subsection{Some Physically Based Models}

The limitations of empirical models in erosion prediction have stimulated an increase in research, in the sense of developing physically based models that are capable of estimating soil losses for a greater number of situations and for shorter periods of time, in contrast to the average values that are provided by the empirical models. Among the various methodologies of this kind that have been disseminated, as a result of several research works developed in different parts of the world, we present briefly some models of this nature. 


\subsubsection{The EPIC Model}

This computer model, called the Erosion/Productivity Impact Calculator, was developed to determine the relationship between soil erosion and productivity in the United States, and continuously simulates the processes associated with erosion on a daily scale, using easily available data [46]. It addresses nine main aspects, namely hydrology, climate, erosion, nutrients, plant growth, soil temperature, crops, control of the plant environment, and the economy. The model applies to small basins, approximately $1 \mathrm{ha}$, in which the soils and the form of use are considered homogeneous, despite being able to consider variations in soil depth and can divide the profile up to a maximum of 10 horizons.

The hydrological component of the model considers the parameters of runoff, which integrates the runoff volume-determined in function of the daily amounts of rainfall, using a modification of the runoff number $(\mathrm{CN})$ technique of the Soil Conservation Services (SCS) of the United States Department of Agriculture-and the peak flow rate based on a modification of the Rational Formula. The percolation uses the technique of directing the storage to simulate the movement of water through the horizons of the profile, and the lateral subsurface movement is calculated simultaneously with the percolation. Evapotranspiration, which in the model is calculated using two estimation methods-Priestley-Taylor and Penman-, includes the determination of potential evapotranspiration and evaporation of plants and soil. The hydrological component also includes the melting of snow, which depends on daily temperatures and is treated in the same way as rain to determine the volume of runoff, percolation, and the dynamics of the water table, with the model being able to lower or raise its level between maximum and minimum depth input values from the surface.

The climatic component of the model integrates rainfall, air temperature and solar radiation. Since the rainfall component is a first-order Markov chain model, the input data must include the monthly probabilities of rainfall, so information on whether or not rainfall occurred last day. For air temperature and solar radiation, a model is used that simulates these parameters that are mutually correlated with rainfall. For the wind, the average daily speed and its direction are considered as variables. For relative humidity, daily average values are simulated from monthly averages, using a triangular distribution, and these values are adjusted to consider the effects of wet and dry days.

The water erosion component integrates rainfall and runoff, simulating the erosion caused by these and by irrigation, using three equations that are the USLE and two of its modified versions. To estimate the erosion caused by furrow irrigation, MUSLE is used. For wind erosion an equation is used that depends on an index of soil erodibility, a climatic factor, a ridges roughness factor, the length of the field in the prevailing wind direction, and the amount of vegetation cover.

The factors that integrate the nutrient component of the model are nitrogen, represented by the loss of nitrates by runoff, which is estimated considering only 
the topsoil of only $10 \mathrm{~mm}$ in thickness, with the total amount of water leaving this layer equal to the sum of the flow of the subsurface lateral movement of the water and the percolation. The washing of nitrogen in the form of nitrates, its transport by evaporation of water from the soil, the transport of organic nitrogen by sediments, denitrification, mineralization, its immobilization, and the nitrogen added by precipitation, are other variables that are included in this component. Also included here is the soluble phosphorus that is dragged in the runoff water (taking into account that this nutrient is more associated with the sediment phase and it is with them that it is transported) its mineralization, immobilization, and its cycle in the soil.

The average daily temperature in the center of each soil layer is simulated for use in nutrient circulation and hydrology. There is a unique model to simulate the growth of various crops, both annual and perennial from the date of sowing until harvest. In this model, the parameters of potential growth, water use, nutrient absorption, namely the need, supply and fixation of nitrogen and phosphorus are considered. Constraints to plant growth are also estimated by assessing potential biomass, whose parameters considered are the lack of water, temperature, nutrients and aeration, and root growth. Water use, cultural performance and winter dormancy are other determinants of plant growth.

The crop component is designed to mix nutrients and crop residues in the crop layer, simulate the change in real density, lay the residues on the soil surface, with functions that simulate the height of ridges and surface roughness. The control of the plant environment is another component of the model that integrates drainage, irrigation, fertilization, liming, the use of pesticides, and the construction of pits. The economic component is represented by an inventory of the crop and an accounting subsystem that would inventory the production and marketing costs of the crops.

[47] consider that the EPIC is a physically based model capable of simulating realistically and simultaneously erosion processes using easily available data; simulate the processes as they can occur for hundreds of years, if necessary, since erosion can occur relatively slowly; it is applicable to a wide range of soils, climates and crops in the United States; and it is efficient in computer use, convenient and able to assess the effects of management changes on soil erosion and productivity.

\subsubsection{The WEPP Model}

It is a physically based model designed to estimate water erosion on slopes. The Water Erosion Prediction Project (WEPP) was started in 1985 with the aim of developing a new generation of technology for use in planning soil and water conservation [48]. According to [27] WEPP uses a permanent regime sediment continuity equation to predict the laminar and rill processes, based on the fundamentals of infiltration, surface runoff, plant growth, waste decomposition, hydraulics, plowing, management, soil consolidation, and mechanics of erosion. 
This computer model estimates liquid removal and deposition, and uses the concept that rill removal and transport rates are a function of the portion of transport capacity that is filled by sediment. The sediment transport from the laminar runoff areas is considered to be proportional to the square of the rain intensity, with the proportionality constant being the soil erodibility parameter, while the removal of sediments from the furrows is considered to be zero when the rupture occurs at a point less than the critical limit of soil rupture.

It integrates a hydrological component that calculates the variables of the peak flow rate, its effective duration and the effective intensity of the precipitation, thus generating information on the rainfall turning points and the flow hydrographs. The rupture stress of the flow or its ability to remove in the rills, its width, depth and spacing, and the relationship with the sediment load, reflected in its sediment transport capacity are also part of this component.

Erosion calculations are performed by solving dimensionless equations followed by resizing the final solution [27]. The model includes four erosion parameters, all dimensionless, one for laminar erosion, two for rill erosion and one for deposition. The parameters that characterize the removal in furrows are the erodibility of its base, the hydraulic rupture of the soil base determined under standard conditions, and the effect that the residues buried in the soil have in the production of sediments. The laminar erosion parameter integrates soil erodibility, the effective intensity of rainfall, the effect of the canopy, the effect of the surface cover, the spacing of the rills, and their calculated width. The rate of deposition of the particles, which is calculated according to an effective diameter and specific weight at the point of removal, using standard drag ratios, defines the deposition parameter.

[49] considers that the WEPP model predicts out-of-place erosion rates, including sediment harvesting in the slope profile and its enrichment rate, as well as on-site erosion rates, such as removal rates and deposition. [28] distinguish two forms of the model, one being the single rainfall version, which includes the hydrological and erosion models, and the erosion model independent of the hydrology model, while [17] refer to the WEPP model for hydrographic basins, which is composed of four components, namely the slope, the channel, the reservoir and the irrigation.

\subsubsection{The CREAMS Model}

This model is called Chemicals, Flow and Erosion in Agricultural Management Systems (CREAMS) and is a model designed to compensate for USLE's inability to contemplate erosion by concentrated flow or sediment deposition, and for not including variables that adequately describe complex slopes or drainage channels [25].

It fundamentally integrates components to simulate the physical processes that control hydrological processes, erosion and sediment production, and the movement of chemicals in an individual plot. The hydrological component of 
the model uses daily rainfall data and the United States Soil Conservation Services (SCS) runoff process to calculate runoff. The model also has a user manual with basic data on climate, soils and crops. In addition to these, data on the plot area, the average slope of the land, the average depth of the root system of the crop, the porosity of the soil, the average monthly temperatures, solar radiation and the leaf area index are also part of this component.

The parameters that are included in the component of erosion and sediment production are the plot area, detailed slope profiles, channel data, data on soils, crops, management systems, rates of soil loss, the depth of erodible soil, the phases of the crop, and the control of channel exits. This component contains routines for estimating laminar and groove erosion in areas of runoff, channel erosion in concentrated runoff areas, and liquid deposition in temporary reservoirs. Its user manual also contains data on soil loss rates and Manning roughness coefficients.

According to [50], the erosion/sedimentation component uses the results of the hydrological component to calculate erosion and sedimentation caused by runoff, and channel and reservoir runoff, with the runoff erosion element being calculated by a modified USLE. To calculate erosion, a removal ratio based on the rupture stress of the flow in the channel is used, and the Yalin equation to calculate the transport capacity of the flow sediments, with the sedimentation being calculated according to the falling speed of the different dimensions of the particles.

The CREAMS model is able to consider specific characteristics of the site and estimate deposition and erosion in concentrated runoff, and hence its potential to estimate reductions in soil losses motivated by practices such as the installation of drainage channels [25]. In addition, it is capable of simulating erosion processes on complex slopes, thus predicting where erosion and deposition will occur, as well as its effects on the distribution of sediments by size, and estimating soil loss by rainfall or by month.

\subsubsection{The EUROSEM Model}

The European Soil Erosion Model (EUROSEM) was developed to support the design of policies for soil protection [29]. It aims to be able to estimate the risks of erosion, to be applicable to the scales of the plot and the watershed, to determine the distribution of solutes from the earth's surface to aquatic bodies, to provide credible estimates of erosion and concentration of solutes for comparison with acceptable standards, operate on a unique event basis, and be useful as a design tool for selecting soil protection measures.

Its base of operation consists of taking the current and estimated rainfall and runoff as input data, and dealing with the interception of rainfall by plant cover, the removal of soil particles by the impact of raindrops, the removal by runoff, concentrated or diffuse, and transport capacity. Soil loss is calculated by comparing the flow carrying capacity with the supply of sediment made available for 
transportation through the removal process, and erosion can be limited either by the amount of sediment removed or the flow carrying capacity. If the transport capacity is less than the supply of removed sediment, deposition occurs.

The interception of rainfall is one of the parameters of the model that begins with the knowledge of the height of rainfall that occurs in each space of time, from which its volume and intensity are calculated. The amount of precipitation that reaches the surface of the soil depends on the nature of the vegetation cover and the degree of protection given to the soil. The condition of the soil surface is defined by its roughness, expressed by a rate of roughness that is the ratio of the distance of the straight line between two points by the actual distance measured over all microtopographic irregularities.

Information on the generation of runoff for the model can be obtained through measured values or as a result of an appropriate hydrological model. The model separates the flow into two components, one being the depression and the other on the remaining surface. The removal of soil by the impact of raindrops is considered in terms of direct fall and runoff from the leaves of the canopy, and the removal by runoff is modeled as a function of the breaking speed of the particles above a critical value for their movement, which depends on the cohesion of the soil at the saturation point. The flow's carrying capacity to move the removed particles is modeled as a function of the current force, and soil loss, liquid erosion and deposition are calculated by comparing the availability of removed material for transportation and the carrying capacity of the flow.

EUROSEM is considered to be different from most erosion models in its treatment of soil and vegetation, in which soil erodibility is represented as a dynamic property through the use of an index of resistance to rupture and removal, which varies with the cohesion of the structure of the soil surface, taking into account the effect of tillage on the soil through changes in the real density and surface roughness, as the vegetation is modeled through its effects on the volume and energy of the precipitation that reaches the surface of the soil, infiltration, and the roughness given to runoff.

\subsubsection{KYERMO and ANSWERS Models}

The KYERMO model, the Kentucky Erosion Model, was developed with the purpose of serving as an investigation tool to isolate important sub-processes within the global erosion process [24]. The objectives proposed are to be a general structure for erosion and to facilitate additional research, to model the process of erosion by rills and to estimate the global collection of sediments and changes in the middle sections of the rills, on geometric surfaces carefully controlled on slopes accentuated, as a first step to model the erosion process on a stochastic surface.

Its main structure uses a conceptual model for the erosion process in which the parcel is divided into portions of slope and furrow basins in each of them, with the rates of transport and sediment removal calculated in individual fur- 
rows. The main program and the support routines have four components: flow generation, flow targeting, sediment generation and sediment targeting. It consists of 37 subroutines and functions and is written in Microsoft FORTRAN, which is a subset of the standard ANSI FORTRAN 77 and can be run on other computers with minor modifications.

ANSWERS, translated as Areal Nonpoint Source Watershed Environmental Response Simulation, is a physically based model that simulates the flow and transport of sediments at the watershed scale, applicable to basins with an area of up to $100 \mathrm{~km}^{2}$, although its informatized version can only support 1700 cells, its practical limit being $17 \mathrm{~km}^{2}$ when 1 ha cells are used [51].

This model simulates excess rainfall, the orientation of laminar and rill flow, subsurface drainage, and the removal and transport of sediment. Excessive rainfall is obtained by the difference between precipitation and the sum of interception, retention and infiltration. The surface flow is directed from cell to cell using the continuity equation in conjunction with the Manning equation, the part of the flow that is directed from one cell to the adjacent downstream calculated according to the direction of the slope of the cell, and the concentrated flow calculated by the continuity and Manning equations, considering all channels as having a rectangular section.

The rate of sediment removal by precipitation is calculated according to the parameters of the crops and cultural practices, conservative practices and soil erodibility of the USLE, considering the area of the place where precipitation or runoff occurs, the intensity of precipitation and the rate flow per unit width. The model assumes that the deposited sediments are again bound to other surface particles and therefore must be removed again to be available for surface runoff, and that the channels are not erodible.

\section{Conclusions}

The present work consists of a review of methods for estimating soil loss due to water erosion, in order to provide useful information on the options that exist in this field. Although in some cases only a brief reference is made to the different methods, the outline of which is much more complete, the usefulness of this exercise lies in providing different options that can be used, so that one can have a perspective on the meaning of water erosion that occurs under certain conditions. Since soil loss is a process that contributes to land degradation and loss of productivity, its importance is not only environmental, but also has a socio-economic character, hence the usefulness of perception as accurately as possible about its extent and meaning, with a view to its control through better planning of land use.

The choice of the best method to be used in a given context depends on several factors, including the availability of the data that are necessary for the application of the model to be used. The Universal Soil Loss Equation is at the origin of the various models that have been developed, which evolved from this empirical 
equation for those who use the law of conservation of mass, considered as physically based. While empirical methods work according to the "black box" principle, which does not provide an exact understanding of the interactions that occur between erosion factors, the physically based models try to function as a "white box", trying to express transparently the erosion process, in which all the acting mechanisms are visible, since the removal of soil particles, their transport and deposition, when the flow speed decreases.

In any of the cases, that is, whatever the option for the model to be used, the important thing is that it be validated for the place under study, according to the existing data. For this reason, the availability of data is fundamental for the application of the models, which can only be guaranteed by a sound support of research in several matters. In any case, it will be up to the researcher to choose to use the available data so that he can obtain the result as close to reality as possible, when there is a need to produce essential information for planning. This study thus intends to be a contribution to stimulate research on soil conservation, especially in realities where it is fundamental for protection of the environment and for the economy.

\section{Conflicts of Interest}

The author declares no conflicts of interest regarding the publication of this paper.

\section{References}

[1] Richter, G. (1978) Soil Erosion Mapping in Germany and in Czechoslovakia. In: De Boodt, M. and Gabriels, D., Eds., Assessment of Erosion, John Wiley \& Sons, Hoboken, 29-50.

[2] Evans, R.B. (1986) Monitoring Soil Erosion in England and Wales. In: Morgan, R. and Rickson, R., Eds., Erosion Assessment and Modelling, Commission of the European Communities, Brussels, 93-117.

[3] Evans, R. (1978) Characteristics of Water-Eroded Fields in Lowland England. In: Gabriels, G.D. and De Boodt, M., Eds., Assessment of Erosion, John Wiley \& Sons, Hoboken, 77-87.

[4] Auzet, A. (1990) An Approach to the Assessment of Erosion Forms and Erosion Risk on Agricultural Land in the Northern Paris Basin, France. In: Boardman, F.A., Ed., Soil Erosion on Agricultural Land, Wiley, Hoboken, 383-400.

[5] Hasholt, B. (1986) On the Assessment of Soil Erosion in Denmark. In: Morgan, R.P. and Rickson, R.J., Eds., Erosion Assessment and Modelling, Commission of the European Communities, Brussels, 55-72.

[6] Stephens, H.V., Scholl, H.E. and Gaffney, J.W. (1977) Use of the Universal Soil Loss Equation in Wide-Area Soil Loss Surveys in Maryland. In: America, S.C., Ed., Soil Erosion Prediction and Control, Purdue University, West Lafayete, Indiana, 277-282.

[7] Tajek, J. and Merchant, J.R. (1988) Technique to Assess Water Erosion Potential in Northeastern Alberta, Canada. In: Presentation, P., Ed., Session III, 5 th International Soil Conservation Conference, International Soil Conservation Organization, 
Bangkok, 18-19.

[8] Spoomer, R.A. (1986) Concentrated Flow Erosion on Conventional and Conservation Tilled Watersheds. Transactions of the ASAE, 29, 124-127.

https://doi.org/10.13031/2013.30114

[9] Bergsma, E. (1978) Method of Reconnaissance Survey of Erosion Hazard Near Merida, Spain. In: De Boodt, M. and Gabriels, M., Eds., Erosion Assessment, John Wiley \& Sons, Hoboken, 55-66.

[10] Pinczés, Z., Kerényi, A., Erdös-Marton, K. and Csorba, P. (1980) Judgement of the Danger of Erosion through the Evaluation of Regional Conditions. In: Mrgan, R., Ed., Soil Conservartion, Problems and Prospects, Wiley, Hoboken, 87-103.

[11] Gabriels, D.C. (1986) Provisional Rain Erosivity Maps for Some EC Countries. In: Morgan, R. and Rickson, R., Eds., Erosion Assessment and Modelling, Commission of the European Communities, Brussels, 93-117.

[12] Coutinho, M.A. (1994) Caracterização da erosividade da precipitação no sul de Portugal. Recursos Hídricos, 13, 25-31.

[13] Roose, E.J. (1976) Use of the Universal Soil Loss Equation to Predict Erosion in West Africa. Soil Conservation Society of America, 60-74.

[14] Stocking, M.A. and Elwell, H.A. (1973) Soil Erosion Hazard in Rhodesia. Rhodesia Agriculture Journal, 70, 93-101.

[15] Elwell, H. (1979) Modelling Soil Losses in Zimbabwe Rhodesia. University of Manitoba, Manitoba, Winnipeg.

[16] Stocking, M. (1987) A Methodology for Ersoin Hazard Mapping of the SADCC Region. Report No. 9, Soil and Water Conservation and Land Utilization Programme, Maseru, Lesotho, 31 p.

[17] Nearing, M.A., Lane, L.J. and Lopes V.L. (1994) Modeling Soil Erosion. In: Lal, R., Ed., Soil Erosion Research Methods, 2nd Edition, Soil and Water Conservation Society, Ankney, 128-158.

[18] Park, S.W., Mitchel, J.K. and Bubenzer, G.D. (1982) Splash Erosion Modeling: Physical Analysis. Transactions of the ASAE, 25, 357-361.

https://doi.org/10.13031/2013.33535

[19] Yoo, K.H. and Molnau, M. (1982) Simulation of Soil Erosion from Winter Runoff in the Palouse Prairie. Transactions of the ASAE, 25, 1628-1638. https://doi.org/10.13031/2013.33779

[20] Khanbilvardi, R.M. and Rogowski, A.S. (1984) Mathematical Models of Erosion and Deposition on a Watershed. Transactions of the ASAE, 27, 73-79. https://doi.org/10.13031/2013.32738

[21] Gilley, J.E., Woolhiser, D.A. and Mc Whorter, D.B. (1985) Interrill Soil ErosionPart I: Development of Model Equations. Transactions of the ASAE, 28, 147-153. https://doi.org/10.13031/2013.32218

[22] Julien, P.Y. and Simons, D.B. (1985) Sediment Transport Capacity of Overland Flow. Transactions of the ASAE, 28, 755-762. https://doi.org/10.13031/2013.32333

[23] Nearing, M.A., West, L.T. and Brown, L.C. (1988) A Consolidation Model for Estimating Changes in Rill Erodibility. Transactions of the ASAE, 31, 696-700. https://doi.org/10.13031/2013.30769

[24] Hirschi, M.C. and Barfield, B.J. (1988) Kyermo-A Physically Based Research Erosion Model Part I: Model Development. Transactions of the ASAE, 31, 804-813. 
https://doi.org/10.13031/2013.30785

[25] Line, E.D. and Meyer, L.D. (1988) Using the CREAMS Model to Estimate the Effect of Diversion on Soil Loss. Transactions of the ASAE, 31, 1430-1434. https://doi.org/10.13031/2013.30880

[26] Pathak, P., Laryea, K.B. and Saudi, R. (1989) A Runoff Model for Small Watersheds in the Semi-Arid Tropics. Transactions of the ASAE, 32, 1619-1624. https://doi.org/10.13031/2013.31200

[27] Nearing, M.A., Lane, L.J. and Finkner, S.C. (1989) A Process-Based Soil Erosion Model for USDA-Water Erosion Prediction Project Technology. Transactions of the ASAE, 32, 1587-1594. https://doi.org/10.13031/2013.31195

[28] Nearing, M.A., Deer-Ascough, L. and Laflen, J.M. (1990) Sensitivity Analysis of the WEPP Hillslope Profile Erosion Model. Transactions of the ASAE, 33, 839-849. https://doi.org/10.13031/2013.31409

[29] Morgan, R.P.C., Quinton, J.N. and Rickson, R.J (1992) A Soil Erosion Prediction Model for the European Community. In: Hurni, H. and Tato, K., Eds., Erosion, Conservation and Small Scale Farming, Geographica Bernensia, International Soil Conservation Organization (ISCO), World Association of Soil and Water Conservation (WASWC), Bern, 151-162.

[30] Blau, J.B., Woolhiser, D.A. and Lane, L.J. (1988) Identification of Erosion Model Parameters. Transactions of the ASAE, 31, 839-845.

https://doi.org/10.13031/2013.30789

[31] Morgan, R.P.C. (1986) Soil Erosion and Conservation. Longman Scientific and Technical, New York.

[32] Mitchell, J.K. and Bubenzer, G.D. (1980) Soil Loss Estimation. In: Kikby, M.J. and Morgan, R.P.C., Eds., Soil Erosion, John Wiley and Sons, Ltd., Hoboken, 17-62.

[33] Wischmeier, W.H. and Smith, D.D. (1978) Predicting Rainfall Erosion Losses-A Guide to Conservation Planning. Agriculture Handbook No. 282, USDA.

[34] Sebastião, S. and Pereira, L.S. (1994) Estimativa das perdas de solo por erosão em solos agrícolas. Departamento de Engenharia Rural, Instituto Superior de Agronomia, Universidade Técnica de Lisboa, Lisbon, Portugal.

[35] Foster, G.R., Mccool, D.K., Renard, K.G. and Moldenhauer, W.C. (1981) Conversion of the Universal Soil Loss Equation to SI Metric Units. Journal of Soil and Water Conservation, 36, 355-359.

[36] Roose, E.J. (1978) Approach to the Definition of Rain Erosivity and Soil Erodibility in West Africa. In: De Boodt, M. and Gabriels, D., Eds., Assessment of Erosion Chichester, John Wiley \& Sons, Hoboken.

[37] Hudson, N.W. (1992) Soil Conservation. B.T. Batsford Limited, London.

[38] Lal, R. and Elliot, W. (1994) Erodibility and Erosivity. In: Lal, R., Ed., Soil Erosion Research Methods, 2nd Edition, Soil and Water Conservation Society, Ankeny, 181-210. https://doi.org/10.1201/9780203739358-8

[39] Cooley K.R. and Williams, J.R. (1985) Applicability of the Universal Soil Loss Equation (USLE) and Modified USLE to Hawai. In: El-Swafi, S.A., et al., Eds., Soil Erosion and Conservation, Soil Conservation Society of America, Iowa, 509-528.

[40] SWCS (1995) Revised Universal Soil Loss Equation, User Guide, Version 1.04. Soil and Water Conservation Society, Ankeny.

[41] Renard, K.G., Laflen, J.M., Foster, G.R. and Mccool, D.K. (1994) the Revised Soil Loss Equation. In: Lal, R., Ed., Soil Erosion Research Methods, Chapter 5, 2nd Edi- 
tion, Soil and Water Conservation Society, Ankeny, 105-126. https://doi.org/10.1201/9780203739358-5

[42] Brown and Foster (1987) Cited in [34] Sebastião, S. and Pereira, L.S. (1994) Estimativa das perdas de solo por erosão em solos agrícolas. Departamento de Engenharia Rural, Instituto Superior de Agronomia, Universidade Técnica de Lisboa, Lisbon, Portugal.

[43] Renard, K.G., Lane, L.J., Foster, G.R. and Laflen, J.M. (1995) Soil Loss Estimation. In: Agassi, M., Ed., Soil Erosion, Conservation and Rehabilitation, Marcel Decker Inc., New York, 169-201.

[44] Elwell, H. (1980) A Soil Loss Estimator Technique for Southern Africa. In: Morgan, R., Ed., Soil Loss Conservation, Problems and Prospects, Wiley, Hoboken, 281-292.

[45] Foster G.R. (1981) Conservation Practices in Erosion Models. In: Morgan, R.P.C., Ed., Soil Conservation, Problems and Prospects, John Wiley \& Sons, Hoboken, 273-278.

[46] Williams, J.R., Jones, C.A. and Dyke, P.T. (1990) Model Documentation. In: In: Sharpley, A.N. and Williams, J.R., Eds., The EPIC Model: EPIC-Erosion/Productivity Impact Calculator, Technical Bulletin, No. 1768, US Department of Agriculture, Washington DC.

[47] Williams, J.R., Dyke P.T., Fuchs, W.W., Benson, V.W., Rice, O.W. and Taylor, E.D. (1990) User Manual. Vol. 2 of EPIC-Erosion/Productivity Impact Calculator, Technical Bulletin No. 1786, US Department of Agriculture, Washington DC.

[48] Foster, G.R. and Lane, L.J. (1987) Cited in [28] Nearing, M.A., Deer-Ascough, L. and Laflen, J.M. (1990) Sensitivity Analysis of the WEPP Hillslope Profile Erosion Model. Transactions of the ASAE, 33, 839-849. https://doi.org/10.13031/2013.31409

[49] Chaves, H.M.L. and Nearing, M.A. (1991) Uncertainty Analysis of the WEPP Soil Erosion Model. Transactions of the ASAE, 34, 2437-2444. https://doi.org/10.13031/2013.31890

[50] Ewing, L.K. (1989) CREAMS Representation for Hidrology and Sedimentology of Central Illinois. Transactions of the ASAE, 32, 1599-1604. https://doi.org/10.13031/2013.31197

[51] Montas, H.J. and Madramootoo, C.A. (1991) Using the Answers Model to Predict Runoff and Soil Loss in Eouthwestern Quebec. Transactions of the ASAE, 34, 1754-1762. https://doi.org/10.13031/2013.31797 